\title{
Analysis and Applicability of Heffron-Phillips Model
}

\author{
Jozef Ritonja $^{1}$, Martin Petrun ${ }^{1}$, Jernej Cernelic ${ }^{1}$, Robert Brezovnik ${ }^{1}$, Bostjan Polajzer ${ }^{1}$ \\ ${ }^{I}$ Faculty of Electrical Engineering and Computer Science, University of Maribor, \\ Smetanova ulica 17, SI-2000 Maribor, Slovenia \\ jozef.ritonja@um.si
}

\begin{abstract}
In this paper, a non-linear $7^{\text {th }}$ order dynamic model and a linearized $3^{\text {rd }}$ order dynamic model of a synchronous generator connected to an infinite bus are presented and compared in details. Parameters and equations of the both models are explained and summarized. They represent a useful starting point for work in areas of synchronous generators' construction, analysis, control systems design and synthesis.

Novelty of this work represents a detailed research of applicability of the linearized model in an entire operating range. Established theoretical conclusions were confirmed with numerical results. Restrictions of utilizing the linearized model are presented. On a basis of the analysis for the synchronous generators of different power, their applicability with feasibility and accuracy was evaluated by certain objective criteria.
\end{abstract}

Index Terms-Heffron-Phillips model; numerical analysis; power system dynamics; synchronous generators.

\section{INTRODUCTION}

The synchronous generators (SG) are most important sources of electric energy. Consequently, there is a distinct interest in adequate static and dynamic models of SG. These models accelerate the design and the construction of SG, facilitate the analysis and simulation of operating of SG and enable the systematic synthesis of their control systems [1].

In the references [1]-[3], an excess number of the SG's models of varying degrees of complexity are presented. The simplest SG's model is a "voltage behind synchronous reactance model" or a "classical model" where SG is represented with a network of constant voltage and single series reactance. On the other side, the most thorough SG's model is the "non-linear $7^{\text {th }}$ order d-q model" (N7OM), where magnetic coupling of stator-, field- and damperwindings is a function of a position and saturation of a rotor. The windings' equations are transformed and presented in a form of a non-linear state-space model. Between these two extreme models, we can find many SG's models with a different grade of complexity. Especially important is the "linearized $3^{\text {rd }}$ order model" (L3OM), called also "HeffronPhillips model" [4]. This model has a very good ratio between complexity and accuracy.

Manuscript received 10 November, 2015; accepted 11 June, 2016.
L3OM correctly describes dynamics of the synchronous generator only in proximity of an equilibrium state. Limitations of utilization of L3OM are presented in its early references [1], [4]. In that period, critical assessments of usage of L3OM are carried out. Numerous attempts of modification of L3OM toward its generalization and larger functionality are conducted [5], [6]. However, none of those attempts replaced an original version of L3OM.

Despite accuracy of L3OM in the entire operating range is questionable, L3OM is still frequently used instead of N7OM in many works concerned with the dynamics of SG [1]-[7]. The main reason to use L3OM are its simple linear structure, which allows use of linear methods for a model analysis, and a small number of known SG's data necessary for calculation of model's coefficients.

Various authors draw an incomplete generalization of similar enough results between L3OM and N7OM (e.g. [8][10]). This may lead to inappropriate usage of the models. Namely, although the results could be satisfactory in certain conditions, this may not be the case under different conditions. The L3OM namely assures accurate results only in relative proximity of an initial steady-state. It is not certain if the obtained simulation results are accurate. $\mathrm{N} 7 \mathrm{OM}$ is the superior one and that in general L3OM cannot replace N7OM. However, there are certain niches where L3OM seems adequate. A goal of the presented work is to explore applicability of L3OM involving certain operating areas and limits in where it can replace N7OM without significantly lacking accuracy.

In Sections II and III of this paper, N7OM and L3OM are presented in a unifying way displaying the complexity of the both models and the demand for the SG's data. Such description helps to select a proper model for case-by-case scenarios. In Section IV, studied SG is described. Measured SG's data and the calculated coefficients of the models are presented. Simulation results of the both models of studied SG in small vicinity of the equilibrium state are compared. An analysis of the applicability of L3OM of tested SG in the entire operating range is presented in Section V. A generalized analysis of the applicability of L3OM for SG of a different type and different nominal power is shown in Section VI. The merits and disadvantages of the both models are presented in Section VII. A summary and conclusions are written in Section VIII. 


\section{NON-LINEAR 7-TH ORDER MODEL OF SYNCHRONOUS GENERATOR}

Considered SG is assumed to have three stator windings, one field winding and two damper windings, which are magnetically coupled. The SG is connected to a large power system with constant frequency and constant voltage (an infinite bus) through a transmission line. An original model represents six flux linkage equations with self- and mutualstator and rotor inductances [1], [2]. This model is transformed by means of Park's matrix transformation into a model with orthogonal axes, i.e. the N7OM model. The machine equations are formulated in a state-space form. The model's inputs are mechanical torque $T_{\mathrm{m}}(t)$ and rotor excitation winding voltage $v_{\mathrm{f}}(t)$. The model's state-space variables are stator $\mathrm{d}$-axis flux linkage $\lambda_{\mathrm{d}}(t)$, stator q-axis flux linkage $\lambda_{\mathrm{q}}(t)$, rotor excitation winding flux linkage $\lambda_{\mathrm{F}}(t)$, rotor $\mathrm{d}$-axis damper winding flux linkage $\lambda_{\mathrm{D}}(t)$, rotor q-axis damper winding flux linkage $\lambda_{\mathrm{D}}(t)$, mechanical rotor speed $\omega(t)$ and electric rotor angle $\delta(t)$.

The necessary parameters and steady-state quantities of SG to calculate the coefficients and initial conditions of N7OM are presented in Table I.

\begin{tabular}{|c|c|}
\hline \multicolumn{2}{|c|}{ TABLE I. SG'S DATA FOR N7OM. } \\
\hline Parameters of SG & $\begin{array}{c}L_{\mathrm{d}}[\mathrm{H}], L_{\mathrm{q}}[\mathrm{H}], L_{\mathrm{d}}{ }^{\prime}[\mathrm{H}], L_{\mathrm{d}}{ }^{\prime}[\mathrm{H}], l_{\mathrm{d}}[\mathrm{H}], l_{\mathrm{q}}[\mathrm{H}], \\
R_{\mathrm{S}}[\Omega], R_{\mathrm{F}}[\Omega], R_{\mathrm{D}}[\Omega], R_{\mathrm{Q}}[\Omega], R_{\mathrm{e}}[\Omega], L_{\mathrm{e}}[\mathrm{H}], \\
H[\mathrm{~s}]\end{array}$ \\
\hline $\begin{array}{c}\text { Steady-state } \\
\text { quantities of SG }\end{array}$ & $P[\mathrm{~W}], Q[\mathrm{VAr}], \omega_{\mathrm{s}}\left[\mathrm{rad} \mathrm{s}^{-1}\right], V_{\infty}[\mathrm{V}]$ \\
\hline
\end{tabular}

The parameters in Table I: $L_{\mathrm{d}}$ and $L_{\mathrm{q}}$ are d- and q-axes inductances; $L_{\mathrm{d}}$ ' and $L_{\mathrm{d}}$ "' are d-axis transient and subtransient inductances; $l_{\mathrm{d}}$ and $l_{\mathrm{q}}$ are $\mathrm{d}$ - and q-axes leakage inductances; $R_{\mathrm{F}}, R_{\mathrm{D}}, R_{\mathrm{Q}}$ are stator-, field-, d-axis dampingand q-axis damping- windings resistances; $H$ is an inertia constant; $R_{\mathrm{e}}$ and $L_{\mathrm{e}}$ are transmission line resistance and reactance, respectively. The steady-state quantities in Table I: $P$ and $Q$ are active and reactive power at a machine terminal; $\omega_{\mathrm{s}}$ is electric synchronous speed and $V_{\infty}$ is infinite bus voltage.

All the determined parameters and symbols must be normalized on base quantities. To convert dimensional to normalized quantities and conversely, the base quantities presented in Table II are required.

\section{TABLE II. SG'S BASE QUANTITIES.}

\begin{tabular}{|c|c|}
\hline $\begin{array}{c}\text { Primary base } \\
\text { quantities }\end{array}$ & $S_{\text {base }, 1 \mathrm{p}}[\mathrm{VA}], V_{\text {base,L } 0}[\mathrm{~V}], \omega_{\text {base }}\left[\mathrm{rad} \mathrm{s}^{-1}\right]$, \\
\hline $\begin{array}{c}\text { Secondary stator } \\
\text { base quantities }\end{array}$ & $I_{\text {base }}[\mathrm{A}], R_{\text {base }}[\Omega], L_{\text {base }}[\mathrm{H}]$ \\
\hline $\begin{array}{c}\text { Quantity for } \\
\text { conversion between } \\
\text { stator and rotor } \\
\text { base quantities }\end{array}$ & $I_{\mathrm{F} 0}[\mathrm{~A}]$ \\
\hline $\begin{array}{c}\text { Field and damping } \\
\text { base quantities }\end{array}$ & $\begin{array}{c}I_{\text {Fbase }}[\mathrm{A}], V_{\text {Fbase }}[\mathrm{V}], R_{\text {Fbase }}[\Omega], L_{\text {Fbase }}[\mathrm{H}], \\
R_{\text {Dbase }}[\Omega], L_{\text {Dbase }}[\mathrm{H}], R_{\mathrm{Qbase}}[\Omega], L_{\mathrm{Qbase}}[\mathrm{H}]\end{array}$ \\
\hline
\end{tabular}

Meaning of symbols in Table II: $S_{\text {base, } 1 \mathrm{p}}$ is stator base power, which is equal to rated one-phase apparent power; $V_{\text {base,Lo }}$ is stator base voltage, which is equal to an effective stator rated line to neutral voltage; $\omega_{\text {base }}$ is equal to electric synchronous speed; $I_{\text {base }}, R_{\text {base }}$ and $L_{\text {base }}$ are calculated stator base current, resistant and inductance, respectively; $I_{\mathrm{F} 0}$ is field current corresponding to the rated stator voltage on an air gap line; $I_{\text {Fbase }}, V_{\text {Fbase }}, R_{\text {Fbase}}, L_{\text {Fbase }}, R_{\text {Dbase }}, L_{\text {Dbase }}, R_{\text {Qbase }}$ and $L_{\mathrm{Qbase}}$ are field and damping current, voltage, resistance and inductance base quantities.

For N7OM, all the SG's parameters and variables must be normalized by means of the presented base values. The inputs and state-space variables of N7OM are collected in Table III. All inputs and variables except an electric rotor angle are normalized.

TABLE III. N7OM'S INPUTS AND STATE-SPACE VARIABLES.

\begin{tabular}{|c|c|}
\hline Inputs of N7OM & $T_{\mathrm{m}}(t), v_{\mathrm{f}}(t)$ \\
\hline $\begin{array}{c}\text { State-space } \\
\text { variables of N7OM }\end{array}$ & $\lambda_{\mathrm{d}}(t), \lambda_{\mathrm{q}}(t), \lambda_{\mathrm{F}}(t), \lambda_{\mathrm{D}}(t), \lambda_{\mathrm{Q}}(t), \omega(t), \delta(t)$ \\
\hline
\end{tabular}

For shorter description of N7OM, auxiliary coefficients should be calculated with (1)-(7) [1]:

$$
\begin{gathered}
L_{\mathrm{AD}}=L_{\mathrm{d}}-l_{\mathrm{d}}, \\
L_{\mathrm{AQ}}=L_{\mathrm{q}}-l_{\mathrm{q}}, \\
l_{\mathrm{F}}=L_{\mathrm{AD}} \frac{L_{\mathrm{d}}^{\prime}-l_{\mathrm{d}}}{L_{\mathrm{d}}-L_{\mathrm{d}}^{\prime}}, \\
l_{\mathrm{D}}=\frac{L_{\mathrm{AD}} l_{\mathrm{F}}\left(L_{\mathrm{d}}^{\prime \prime}-l_{\mathrm{d}}\right)}{L_{\mathrm{AD}} l_{\mathrm{F}}-\left(l_{\mathrm{F}}+L_{\mathrm{AD}}\right)\left(L_{d}^{\prime \prime}-l_{\mathrm{d}}\right)}, \\
l_{\mathrm{Q}}=L_{\mathrm{AQ}} \frac{L_{\mathrm{d}}^{\prime \prime}-l_{\mathrm{d}}}{L_{\mathrm{q}}-L_{\mathrm{d}}^{\prime \prime}}, \\
\frac{1}{L_{M D}}=\frac{1}{L_{A D}}+\frac{1}{l_{d}}+\frac{1}{l_{F}}+\frac{1}{l_{D}}, \\
\frac{1}{L_{M Q}}=\frac{1}{L_{A Q}}+\frac{1}{l_{q}}+\frac{1}{l_{Q}} .
\end{gathered}
$$

The N7OM is now described by sets of algebraic equations (8)-(17) [1]:

$$
\begin{gathered}
\lambda_{\mathrm{AD}}(t)=L_{\mathrm{MD}}\left(\frac{\lambda_{\mathrm{d}}(t)}{l_{\mathrm{d}}}+\frac{\lambda_{\mathrm{F}}(t)}{l_{\mathrm{F}}}+\frac{\lambda_{\mathrm{D}}(t)}{l_{\mathrm{D}}}\right), \\
\lambda_{\mathrm{AQ}}(t)=L_{\mathrm{MQ}}\left(\frac{\lambda_{\mathrm{q}}(t)}{l_{\mathrm{q}}}+\frac{\lambda_{\mathrm{Q}}(t)}{l_{\mathrm{Q}}}\right), \\
i_{\mathrm{d}}(t)=\frac{1}{l_{\mathrm{d}}}\left(\lambda_{\mathrm{d}}(t)-\lambda_{\mathrm{AD}}(t)\right), \\
i_{\mathrm{q}}(t)=\frac{1}{l_{\mathrm{q}}}\left(\lambda_{\mathrm{q}}(t)-\lambda_{\mathrm{AQ}}(t)\right), \\
i_{\mathrm{F}}(t)=\frac{1}{l_{\mathrm{F}}}\left(\lambda_{\mathrm{F}}(t)-\lambda_{\mathrm{AD}}(t)\right), \\
i_{\mathrm{D}}(t)=\frac{1}{l_{\mathrm{D}}}\left(\lambda_{\mathrm{D}}(t)-\lambda_{\mathrm{AD}}(t)\right), \\
i_{\mathrm{Q}}(t)=\frac{1}{l_{\mathrm{Q}}}\left(\lambda_{\mathrm{Q}}(t)-\lambda_{\mathrm{AQ}}(t)\right), \\
v_{\mathrm{d}}(t)=-\sqrt{3} V_{\infty} \sin (\delta(t))+R_{\mathrm{e}} i_{\mathrm{d}}(t)+\omega(t) L_{\mathrm{e}} i_{\mathrm{q}}(t), \\
v_{\mathrm{q}}(t)=\sqrt{3} V_{\infty} \cos (\delta(t))+R_{\mathrm{e}} i_{\mathrm{q}}(t)+\omega(t) L_{\mathrm{e}} i_{\mathrm{d}}(t), \\
T_{\mathrm{e}}(t)=\frac{1}{3}\left(i_{\mathrm{q}}(t) \lambda_{\mathrm{d}}(t)-i_{\mathrm{d}}(t) \lambda_{\mathrm{q}}(t)\right),
\end{gathered}
$$


and differential equations (18)-(24) [1]:

$$
\begin{gathered}
\dot{\lambda}_{\mathrm{d}}(t)=\omega_{\mathrm{S}}\left(-R_{\mathrm{S}} i_{\mathrm{d}}(t)-\omega(t) \lambda_{\mathrm{q}}(t)-v_{\mathrm{d}}(t)\right), \\
\dot{\lambda}_{\mathrm{q}}(t)=\omega_{\mathrm{S}}\left(-R_{\mathrm{S}} i_{\mathrm{q}}(t)+\omega(t) \lambda_{\mathrm{d}}(t)-v_{\mathrm{q}}(t)\right), \\
\dot{\lambda}_{\mathrm{F}}(t)=\omega_{\mathrm{S}}\left(-R_{\mathrm{F}} i_{\mathrm{F}}(t)+v_{\mathrm{F}}(t)\right), \\
\dot{\lambda}_{\mathrm{D}}(t)=\omega_{\mathrm{S}}\left(-R_{\mathrm{D}} i_{\mathrm{D}}(t)\right), \\
\dot{\lambda}_{\mathrm{Q}}(t)=\omega_{\mathrm{S}}\left(-R_{\mathrm{Q}} i_{\mathrm{Q}}(t)\right), \\
\dot{\omega}(t)=\frac{1}{2 H}\left(T_{\mathrm{m}}(t)-T_{\mathrm{e}}(t)\right), \\
\dot{\delta}(t)=\omega_{\mathrm{S}}(\omega(t)-1),
\end{gathered}
$$

where $i_{\mathrm{d}}(t)$ and $i_{\mathrm{q}}(t)$ are the stator $\mathrm{d}$ - and q-axis currents, $i_{\mathrm{F}}(t)$ is field current, $i_{\mathrm{D}}(t)$ and $i_{\mathrm{Q}}(t)$ are damping $\mathrm{d}$ - and q-axis currents, $v_{\mathrm{d}}(t)$ and $v_{\mathrm{q}}(t)$ are stator terminal $\mathrm{d}$ - and q-axis voltages, $\lambda_{\mathrm{AD}}(t)$ and $\lambda_{\mathrm{AQ}}(t)$ are $\mathrm{d}$ - and q-axis mutual flux linkages and $T_{\mathrm{e}}(t)$ is an electromagnetic torque. All variables in (1)-(24) are normalized on the base quantities from Table II except mechanical torque $T_{\mathrm{m}}(t)$ and electric torque $T_{\mathrm{e}}(t)$, which are normalized on three-phase power base $S_{\text {base,3p }}=3 S_{\text {base,1p }}$ and mechanical speed $\omega(t)$, respectively. The speed is normalized on base value $\omega_{\text {mbase }}=\omega_{\mathrm{s}} / p$, where $p$ is a number of pole pairs. In this way, dimensional mechanical speed can be directly calculated from normalized mechanical speed. Electric rotor angle $\delta(t)$ has unit [rad].

\section{LINEARIZED 3-RD ORDER MODEL OF SYNCHRONOUS GENERATOR}

Main disadvantage of N7OM is its un-suitability for an analytical dynamic analysis and control system design [11]. Additional weakness of N7OM represents difficult tests for measurement and calculation of the SG's data. This is the reason that many simplified models of $\mathrm{SG}$ can be found in references [1]-[3]. Their simplification is made up by neglecting some less important electromechanical phenomena. In such a way, linearized reduced order models of SG are established. Among many linearized reduced orders models, L3OM is the most popular. For development of this model, following assumptions are made [1]:

- balanced conditions are assumed and saturation effects are neglected,

- stator winding resistance is neglected,

- damping phenomena are neglected,

$-\dot{\lambda}_{\mathrm{d}}(t)$ and $\dot{\lambda}_{\mathrm{q}}(t)$ terms in stator equations are neglected and compared against speed voltage terms $\omega(t) \lambda_{\mathrm{d}}(t)$ and $\omega(t) \lambda_{\mathrm{q}}(t)$

- terms $\omega(t) \lambda_{\mathrm{d}}(t)$ in stator and voltage equation are assumed to be approximately equal to $\omega_{\mathrm{s}}(t) \lambda_{\mathrm{d}}(t)$.

Under the assumptions above, L3OM is obtained from N7OM by means of linearization for an every steady-state operating point (i.e. an equilibrium point). The L3OM describes the SG's dynamics in proximity of the selected equilibrium point. The L3OM has two inputs and three statespace variables. The inputs are mechanical torque $T_{\mathrm{m} \Delta}(t)$ and rotor excitation winding voltage $v_{\mathrm{f} \Delta}(t)$ deviations, the statespace variables are rotor angle $\delta_{\Delta}(t)$, rotor speed $\omega_{\Delta}(t)$ and voltage behind transient reactance $e_{\mathrm{q} \Delta}^{\prime}(t)$ deviations.
Additional outputs are electric torque $T_{\mathrm{e} \Delta}(t)$ and terminal stator voltage $v_{\mathrm{t} \Delta}(t)$ deviations. All the inputs and the statespace variables denote the deviations (subscript $\Delta$ ) from the equilibrium state. The minimum set of the parameters and the steady-state variables of: SG, the transmission line and the infinite bus, necessary to calculate the coefficients of L3OM are presented in Table IV.

TABLE IV. SG'S DATA FOR L3OM.

\begin{tabular}{|c|c|}
\hline Parameters of SG & $\begin{array}{c}L_{\mathrm{d}}[\mathrm{H}], L_{\mathrm{q}}[\mathrm{H}], L_{\mathrm{d}}{ }^{\prime}[\mathrm{H}], H[\mathrm{~s}], R_{\mathrm{e}}[\Omega], L_{\mathrm{e}}[\mathrm{H}], \\
D[\mathrm{pu}], T_{\mathrm{d} 0}^{\prime}[\mathrm{s}]\end{array}$ \\
\hline $\begin{array}{c}\text { Steady-state } \\
\text { quantities of SG }\end{array}$ & $P[\mathrm{~W}], Q[\mathrm{VAr}], \omega_{\mathrm{s}}\left[\mathrm{rad} \mathrm{s}^{-1}\right], V_{\infty}[\mathrm{V}]$ \\
\hline
\end{tabular}

New parameters in Table IV are: $D$ is a damping coefficient representing total lumped damping effects and $T^{\prime}{ }_{\mathrm{d} 0}$ is an open circuit time constant of a direct axis.

\begin{tabular}{|c|c|}
\hline $\begin{array}{c}\text { Auxiliary steady- } \\
\text { state } \\
\text { variables for L3OM } \\
\text { coefficients }\end{array}$ & $\delta_{\mathrm{ss}}, v_{\mathrm{d}, \mathrm{ss}}, v_{\mathrm{q}, \mathrm{ss}}, i_{\mathrm{d}, \mathrm{ss}, \mathrm{iq}, \mathrm{ss},} E_{\mathrm{ss}}, E_{\mathrm{q}, \mathrm{ss}}^{\prime}, E_{\mathrm{qa}, \mathrm{ss}}$ \\
\hline
\end{tabular}

From the data in Table IV, the equilibrium state for L3OM is calculated by means of a phasor diagram. Steadystate values in Table $\mathrm{V}$ below must be determined before the calculation of the L3OM coefficients.

TABLE V. AUXILIARY STEADY-STATE VARIABLES FROM PHASOR DIAGRAM FOR L3OM.

Index ss means a steady-state value, while $E, E_{\mathrm{qa}}$ and $E_{\mathrm{q}}$ are standardized phasor diagram EMF.

From the values in Table IV and TableV, linearization coefficients $K_{1}$ to $K_{6}$ of L3OM are calculated [1].

The inputs, the state-space variables and the coefficients of L3OM are collected in Table VI.

TABLE VI. L3OM'S INPUTS, STATE-SPACE VARIABLES AND COEFFICIENTS

\begin{tabular}{|c|c|}
\hline Inputs of L3OM & $T_{\mathrm{m} \Delta}(t), v_{\mathrm{f} \Delta}(t)$ \\
\hline $\begin{array}{c}\text { State-space } \\
\text { variables of L3OM }\end{array}$ & $\omega_{\Delta}(t), \delta_{\Delta}(t), e^{\prime}{ }_{\mathrm{q} \Delta}(t)$ \\
\hline $\begin{array}{c}\text { Coefficients of } \\
\text { L3OM }\end{array}$ & $K_{1}, K_{2}, K_{3}, K_{4}, K_{5}, K_{6}, T^{\prime}{ }_{\mathrm{d} 0}, H, D$ \\
\hline
\end{tabular}

The L3OM is presented in a state-space form by (25) and (26) $[11]$ :

$$
\begin{aligned}
& {\left[\begin{array}{c}
\dot{\delta}_{\Delta}(t) \\
\dot{\omega}_{\Delta}(t) \\
\dot{e}_{\mathrm{\phi} \Lambda}^{\prime}(t)
\end{array}\right]=\left[\begin{array}{ccc}
0 & \omega_{r} & 0 \\
-\frac{K_{1}}{2 H} & -\frac{D}{2 H} & -\frac{K_{2}}{2 H} \\
-\frac{K_{4}}{T_{\mathrm{d} 0}^{\prime}} & 0 & -\frac{1}{K_{3} T_{\mathrm{d} 0}^{\prime}}
\end{array}\right]\left[\begin{array}{l}
\delta_{\Delta}(t) \\
\omega_{\Delta}(t) \\
e_{\mathrm{q} \Delta}^{\prime}(t)
\end{array}\right]+\left[\begin{array}{cc}
0 & 0 \\
\frac{1}{2 H} & 0 \\
0 & \frac{1}{T_{\mathrm{d} 0}^{\prime}}
\end{array}\right]\left[\begin{array}{c}
T_{\mathrm{m} \Delta}(t) \\
v_{\mathrm{f} \Delta}(t)
\end{array}\right],} \\
& {\left[\begin{array}{c}
T_{\mathrm{e} \Delta}(t) \\
v_{\mathrm{t} \Delta}(t)
\end{array}\right]=\left[\begin{array}{lll}
K_{1} & 0 & K_{2} \\
K_{5} & 0 & K_{6}
\end{array}\right]\left[\begin{array}{l}
\delta_{\Delta}(t) \\
\omega_{\Delta}(t) \\
e_{\mathrm{q} \Delta}^{\prime}(t)
\end{array}\right]+\left[\begin{array}{ll}
0 & 0 \\
0 & 0
\end{array}\right]\left[\begin{array}{c}
T_{\mathrm{m} \Delta}(t) \\
v_{\mathrm{f} \Delta}(t)
\end{array}\right] .}
\end{aligned}
$$

All parameters and variables in L3OM are normalized except electric rotor angle $\delta(t)$.

\section{ANAlysis OF DyNAmiC MOdels Of TESTED} SYNCHRONOUS GENERATOR IN VICINITY OF EQUILIBRIUM STATE

To evaluate the suitability and accuracy of the models, salient-pole SG with nominal power $15 \mathrm{kVA}$ was used. 
Manufacturer's data are shown in Table VII.

TABLE VII. MANUFACTURER'S DATA OF TESTED SG.

\begin{tabular}{|c|c|c|c|}
\hline$P_{\mathrm{n}}=12[\mathrm{~kW}]$ & $U_{\mathrm{n}}=400[\mathrm{~V}]$ & $I_{\mathrm{n}}=21.7[\mathrm{~A}]$ & $\cos \varphi_{\mathrm{n}}=0.8$ \\
\hline$U_{\mathrm{Fn}}=400[\mathrm{~V}]$ & $I_{\mathrm{Fn}}=21.7[\mathrm{~A}]$ & $f_{\mathrm{n}}=50[\mathrm{~Hz}]$ & $n_{\mathrm{n}}=1500\left[\mathrm{~min}^{-1}\right]$ \\
\hline
\end{tabular}

The $P_{\mathrm{n}}$ denotes rated active power, $U_{\mathrm{n}}, I_{\mathrm{n}}, U_{\mathrm{Fn}}, I_{\mathrm{Fn}}$ are rated stator and excitation winding voltages and currents, respectively. The $f_{\mathrm{n}}$ and $n_{\mathrm{n}}$ are rated frequency and mechanical speed, respectively.

To determine the SG's parameters, a wide range of testing methods was devised [12], [13]. In a frame of presented work, the standardized steady-state, transient and frequencyresponse tests were used [14], [15]. Obtained SG's parameters are shown in Table VIII.

TABLE VIII. SG'S DATA OBTAINED WITH TESTS.

\begin{tabular}{|l|l|l|l|}
\hline$L_{\mathrm{d}}=2.11[\mathrm{pu}]$ & $L_{\mathrm{q}}=1.45[\mathrm{pu}]$ & $L_{\mathrm{d}}{ }^{\prime}=0.25[\mathrm{pu}]$ & $L_{\mathrm{d}}{ }^{\prime \prime}=0.18[\mathrm{pu}]$ \\
\hline$l_{\mathrm{d}}=0.15[\mathrm{pu}]$ & $l_{\mathrm{q}}=0.15[\mathrm{pu}]$ & $R_{\mathrm{e}}=0.003[\mathrm{pu}]$ & $L_{\mathrm{e}}=0.03[\mathrm{pu}]$ \\
\hline$R_{\mathrm{s}}=0.05[\mathrm{pu}]$ & $R_{\mathrm{F}}=0.015[\mathrm{pu}]$ & $H=0.19[\mathrm{pu}]$ & $D=1[\mathrm{pu}]$ \\
\hline$R_{\mathrm{D}}=0.262[\mathrm{pu}]$ & $R_{\mathrm{Q}}=1.08[\mathrm{pu}]$ & $T^{\prime}{ }_{\mathrm{d} 0}=0.5[\mathrm{~s}]$ & $\omega_{\mathrm{s}}=2 \pi 50\left[\mathrm{~s}^{-1}\right]$ \\
\hline
\end{tabular}

For a nominal operating point, the calculated linearization coefficients are given in Table IX.

TABLE IX. LINEARIZATION PARAMETERS OF L3OM FOR NOMINAL OPERATING POINT $S_{\mathrm{n}}=15 \mathrm{KVA}, \cos \varphi_{\mathrm{n}}=0.8$.

\begin{tabular}{|c|c|c|c|}
\hline$P_{\mathrm{n}}=0.8[\mathrm{pu}]$ & $K_{1}=2.1555$ & $K_{2}=2.0815$ & $K_{3}=0.1285$ \\
\hline$Q_{\mathrm{n}}=0.6[\mathrm{pu}]$ & $K_{4}=3.5155$ & $K_{5}=0.0228$ & $K_{6}=0.0998$ \\
\hline
\end{tabular}

The testing system for determination of the parameter and experiments is shown in Fig. 1.

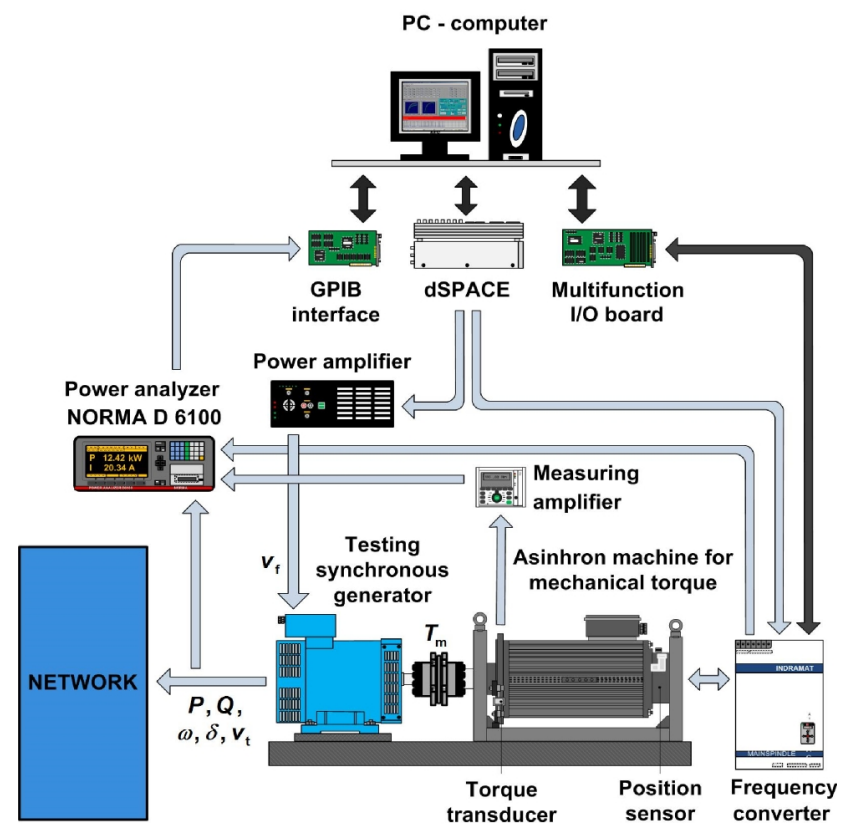

Fig. 1. Testing system.

It is evident from experiments that N7OM well describes responses of real SG to the changes in the both inputs. Agreement in the first amplitude, the frequency and the damping of the transient response is very high. The experiments and the N7OM simulations were carried out in many operating points in the entire operating range of SG. In the entire range, N7OM represents accurate description of the dynamics of real SG.

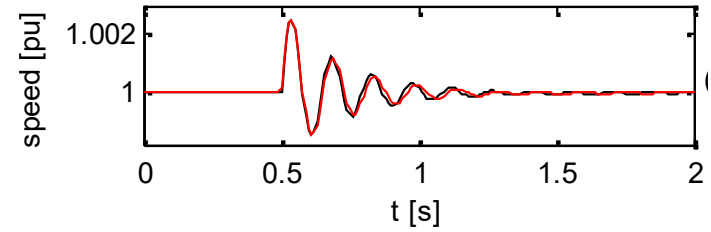

a)

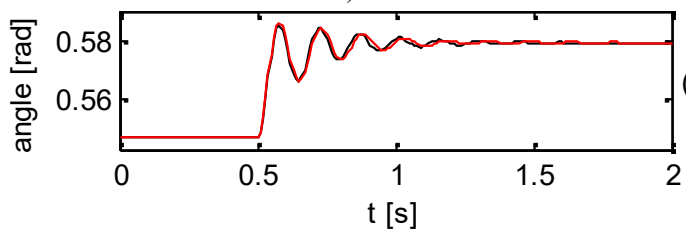

b)

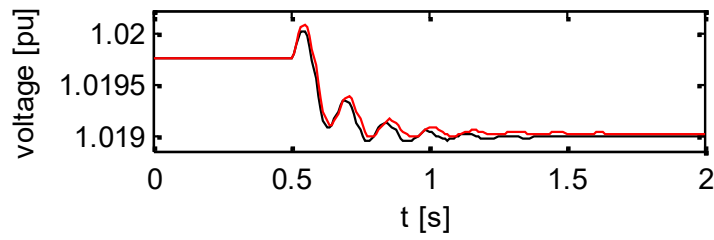

c)

Fig. 2. Rotor speed (a), rotor angle (b) and terminal stator voltage (c) for step change of mechanical torque from $T_{\mathrm{m}}=0.8[\mathrm{pu}]$ to $T_{\mathrm{m}}=0.84[\mathrm{pu}]$ in $t=0.5[\mathrm{~s}]$ obtained with N7OM simulation (black) and L3OM simulation (red).

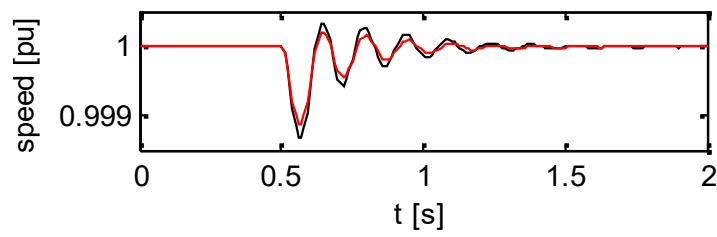

a)

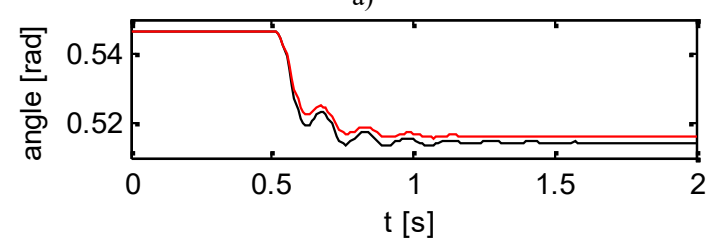

b)

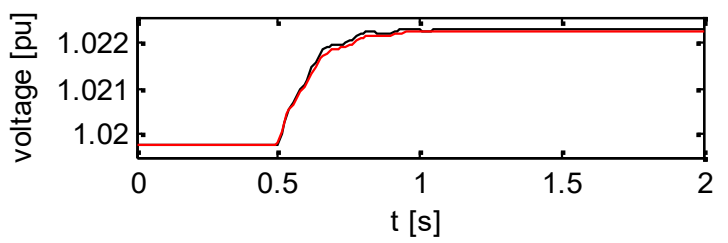

c)

Fig. 3. Rotor speed (a), rotor angle (b) and terminal stator voltage (c) for step change of field excitation voltage from $v_{\mathrm{f}}=2.8$ [pu] to $v_{\mathrm{f}}=2.94[\mathrm{pu}]$ in $t=0.5[\mathrm{~s}]$ obtained with N7OM simulation (black) and L3OM simulation (red).

To evaluate accuracy of the L3OM, simulations of N7OM and L3OM with same inputs and initial conditions were carried out and compared. Figure 2 shows the rotor speed, rotor angle and terminal stator voltage responses to a $5 \%$ step change of the mechanical torque from the nominal operating point (i.e. from $T_{\mathrm{m}}=0.8[\mathrm{pu}]$ to $T_{\mathrm{m}}=0.84[\mathrm{pu}]$ in $t=0.5[\mathrm{~s}]$ ). Figure 3 shows the rotor speed, rotor angle and terminal stator voltage responses to the $5 \%$ step change of the rotor excitation voltage from the nominal operating point (i.e. from $v_{\mathrm{f}}=2.8[\mathrm{pu}]$ to $v_{\mathrm{f}}=2.94[\mathrm{pu}]$ in $t=0.5[\mathrm{~s}]$ ). From the both figures, the high accordance of L3OM is evident. To research suitability of L3OM in an entire operating range of SG (from $P=0[\mathrm{pu}]$ to $P=1.2[\mathrm{pu}]$ and from 
$Q=-1.2[\mathrm{pu}]$ to $Q=1.2[\mathrm{pu}])$, a systemic numerical analysis of the both models in the entire operating range was conducted. The conclusion is that L3OM describes SG's electro mechanical phenomena in the entire operating range in the case of the small input's perturbations.

\section{ANALYSIS OF DYNAMIC MODELS OF TESTED SYNCHRONOUS GENERATOR IN ENTIRE OPERATING RANGE}

Main disadvantage of L3OM is its restriction to use only in "relative" proximity of the equilibrium state. An effect of larger input changes on discrepancy between responses obtained with N7OM and L3OM is shown in Fig. 4 and Fig. 5. Figure 4 shows rotor speed, rotor angle and terminal stator voltage responses to a $50 \%$ step change of a mechanical torque from the nominal operating point (i.e. from $T_{\mathrm{m}}=0.8[\mathrm{pu}]$ to $T_{\mathrm{m}}=1.2[\mathrm{pu}]$ in $\left.t=0.5[\mathrm{~s}]\right)$. Figure 5 shows the same variables' responses to the $50 \%$ step change of field excitation voltage from the nominal operating point (i.e. from $v_{\mathrm{f}}=2.8[\mathrm{pu}]$ to $v_{\mathrm{f}}=4.2[\mathrm{pu}]$ in $t=0.5[\mathrm{~s}]$ ). From the both figures, larger inaccurateness of L3OM can be seen in the steady-state values and in the frequency and the damping of the transient responses.

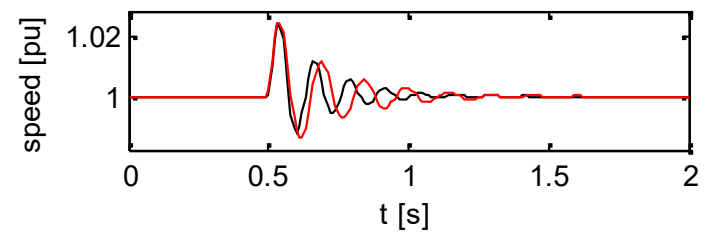

a)

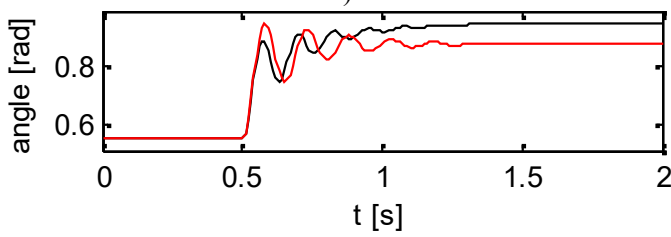

b)

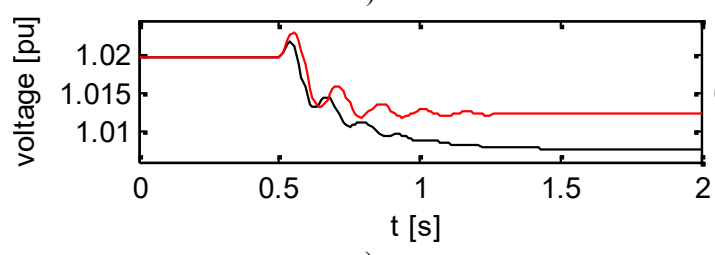

c)

Fig. 4. Rotor speed (a), rotor angle (b) and terminal stator voltage (c) for step change of mechanical torque from $T_{\mathrm{m}}=0.8[\mathrm{pu}]$ to $T_{\mathrm{m}}=1.2[\mathrm{pu}]$ in $t=0.5$ [s] obtained with N7OM simulation (black) and L3OM simulation (red).

Limits of the equilibrium state, where L3OM is accurate enough to replace N7OM are estimated with the systemic numerical analysis. It is carried out in the entire operating range for various inputs. The evaluation of the steady-state accuracy and the dynamic quality of L3OM is made.

Figure 6 shows the influence of mechanical torque deviations on a rotor angle error and on a stator voltage error between N7OM and L3OM in steady-states for a mechanical torque range from $T_{\mathrm{m} \Delta}=-0.5[\mathrm{pu}]$ to $T_{\mathrm{m} \Delta}=+0.5[\mathrm{pu}]$ around a nominal value of the torque. Figure 7 shows influence of field excitation voltage deviations on the rotor angle error and stator voltage error between the N7OM and L3OM in steady-states for deviation of field excitation voltage from $v_{\mathrm{f} \Delta}=-1.0[\mathrm{pu}]$ to $v_{\mathrm{f} \Delta}=+1.0[\mathrm{pu}]$ around the nominal value of the field excitation voltage. On the both figures, the influence of the magnitude of the amplitude of the deviations of the input quantities (from the nominal value) on the steady-state errors is observed.

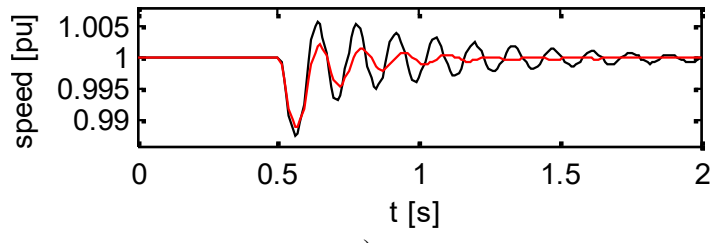

a)

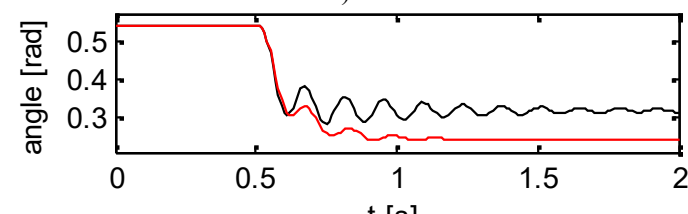

b)

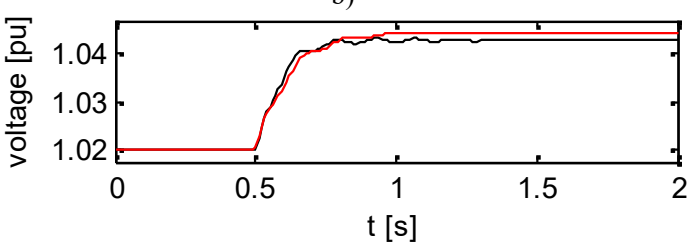

c)

Fig. 5. Rotor speed (a), rotor angle (b) and terminal stator voltage (c) for step change of the field excitation voltage from $v_{\mathrm{f}}=2.8[\mathrm{pu}]$ to $v_{\mathrm{f}}=4.2[\mathrm{pu}]$ in $t=0.5[\mathrm{~s}]$ obtained with N7OM simulation (black) and L3OM simulation (red).
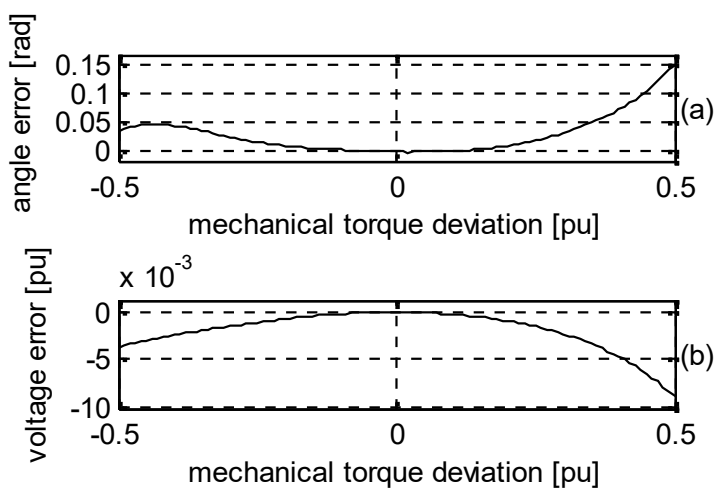

Fig. 6. Rotor angle error (a) and stator voltage error (b) between N7OM and L3OM steady-states for deviation of mechanical torque from $T_{\mathrm{m} \Delta}=-0.5[\mathrm{pu}]$ to $T_{\mathrm{m} \Delta}=+0.5[\mathrm{pu}]$ around nominal value of mechanical torque.

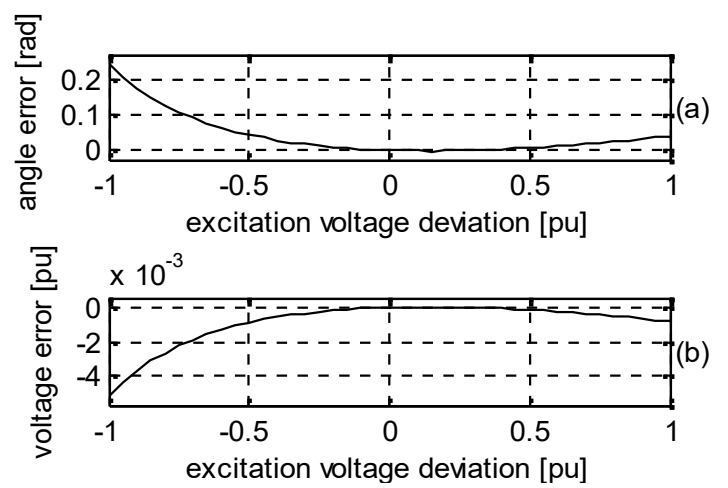

Fig. 7. Rotor angle error (a) and stator voltage error (b) between N7OM and L3OM steady states for deviation of field excitation voltage from $v_{\mathrm{f} \Delta}=-1.0[\mathrm{pu}]$ to $v_{\mathrm{f} \Delta}=+1.0[\mathrm{pu}]$ around nominal value of field excitation voltage.

To research influence of the inputs' deviations on the dynamic accuracy of L3OM, an integral squared error 
between the speed responses of N7OM and L3OM during the transient states was introduced

$$
\operatorname{ISE}=\int\left(\omega_{\mathrm{N} 7 \mathrm{OM}}(t)-\omega_{\mathrm{L} 3 \mathrm{OM}}(t)\right)^{2} \mathrm{~d} t,
$$

where $\omega_{\mathrm{N} 7 \mathrm{OM}}(t)$ and $\omega_{\mathrm{L} 3 \mathrm{OM}}(t)$ denote the rotor electric speed of N7OM and L3OM, respectively during the transient states. Figure 8 shows a square root of an integral squared error as a function of mechanical torque deviation from $T_{\mathrm{m} \Delta}=-0.5[\mathrm{pu}]$ to $T_{\mathrm{m} \Delta}=+0.5[\mathrm{pu}]$ around the nominal value and as a function of field excitation voltage from $v_{\mathrm{f} \Delta}=-1.0[\mathrm{pu}]$ to $v_{\mathrm{f} \Delta}=+1.0[\mathrm{pu}]$ around the nominal value.

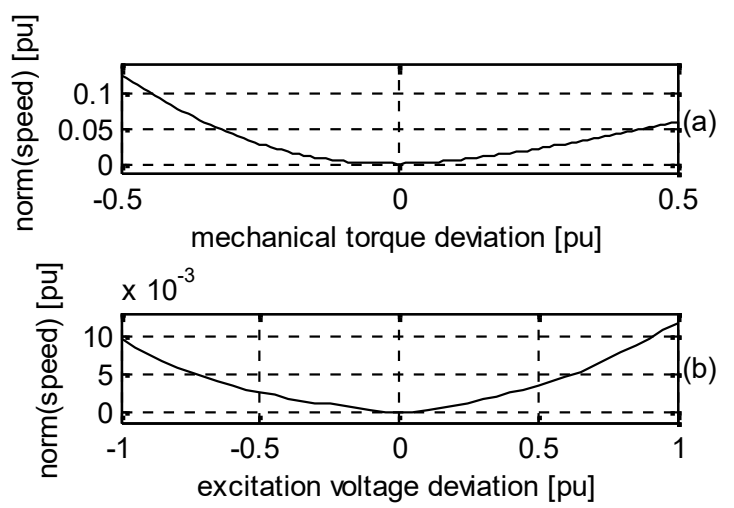

Fig. 8. Square root of integral squared error ("norm(speed)") between rotor speed transients of N7OM and L3OM for: (a) step changes of mechanical torque from $T_{\mathrm{m} \Delta}=-0.5[\mathrm{pu}]$ to $T_{\mathrm{m} \Delta}=+0.5[\mathrm{pu}]$ from nominal value of mechanical torque and (b) step changes of field excitation voltage from $v_{\mathrm{f} \Delta}=-1.0[\mathrm{pu}]$ to $v_{\mathrm{f} \Delta}=+1.0[\mathrm{pu}]$ from nominal value of field excitation voltage.

\section{GENERALIZED ANALYSIS OF DYNAMIC MODELS IN ENTIRE OPERATING RANGE}

By means of diagrams in Fig. 6 to Fig. 8, the steady-state and dynamic errors of L3OM of tested salient-pole SG with nominal power $15 \mathrm{kVA}$ can be estimated. In order to find common conclusions in regards to accuracy of L3OM for all $\mathrm{SG}$, comparison between $\mathrm{N} 3 \mathrm{OM}$ and $\mathrm{L} 3 \mathrm{OM}$ is carried out. In this second phase of the study, different types of SG of different power in the entire operating range for different inputs' deviations and initial conditions are considered. Hydro SG of nominal power from 9 MVA to 615 MVA and turbo SG of nominal power from 25 MVA to 911 MVA were analysed. The data of SG were obtained from [1], [2]. In this paper, only results of 5 significant $\mathrm{SG}$ are presented.

Figure 9 and Fig. 10 show the influence of mechanical torque deviations and excitation voltage on a steady-state rotor angle error and on a steady-state stator voltage error of L3OM for a mechanical torque range from $T_{\mathrm{m} \Delta}=-0.5[\mathrm{pu}]$ to $T_{\mathrm{m} \Delta}=+0.5[\mathrm{pu}]$ and field excitation voltage from $v_{\mathrm{f} \Delta}=-1.0[\mathrm{pu}]$ to $v_{\mathrm{f} \Delta}=+1.0[\mathrm{pu}]$ around a nominal values (similar as in Fig. 6 and Fig. 7) for turbo type SG of nominal values $S_{\mathrm{n}}=25$ MVA, 75 MVA, 160 MVA, 555 MVA and 911 MVA. The manufacturers' data are presented in Appendix A. From the both figures, it is evident that obtained error functions have a same form and very similar values of steady-state errors. The steady-state error characteristics of other turbo- and hydro- types SG are similar in the form and the values.
Figure 11 shows a square root of an integral squared error as a function of mechanical torque deviation from $T_{\mathrm{m} \Delta}=-0.5[\mathrm{pu}]$ to $T_{\mathrm{m} \Delta}=+0.5[\mathrm{pu}]$ around the nominal value and as a function of field excitation voltage from $v_{\mathrm{f} \Delta}=-1.0[\mathrm{pu}]$ to $v_{\mathrm{f} \Delta}=+1.0[\mathrm{pu}]$ around the nominal value for five analysed SG. Others SG have similar responses. Due to this reason, they are not displayed in the paper.
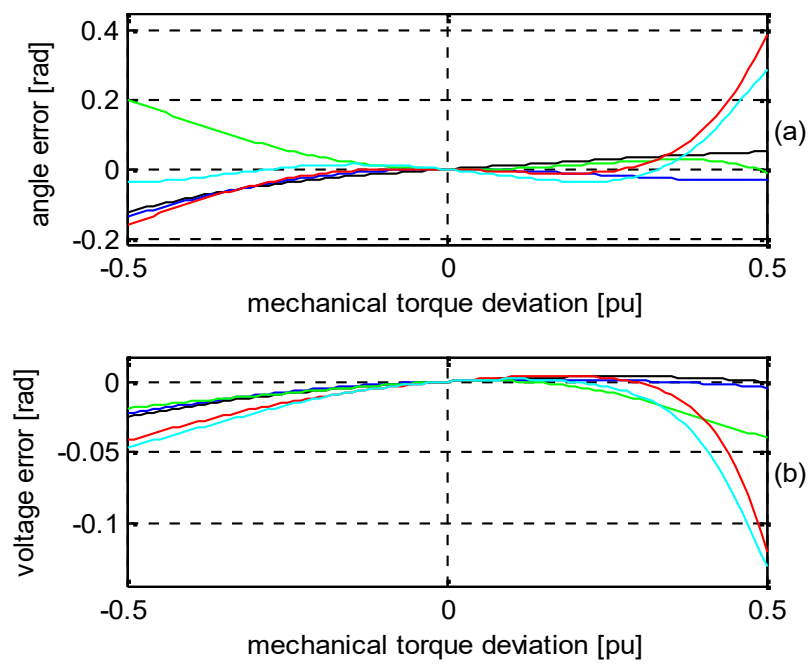

Fig. 9. Rotor angle error (a) and stator voltage error (b) between N7OM and L3OM steady-states for deviation of mechanical torque from $T_{\mathrm{m} \Delta}=-0.5[\mathrm{pu}]$ to $T_{\mathrm{m} \Delta}=+0.5[\mathrm{pu}]$ around nominal value for turbo type SG of nominal powers $\mathrm{Sn}=25$ MVA (black), 75 MVA (blue), 160 MVA (green), 555 MVA (red), 915 MVA (cyan).
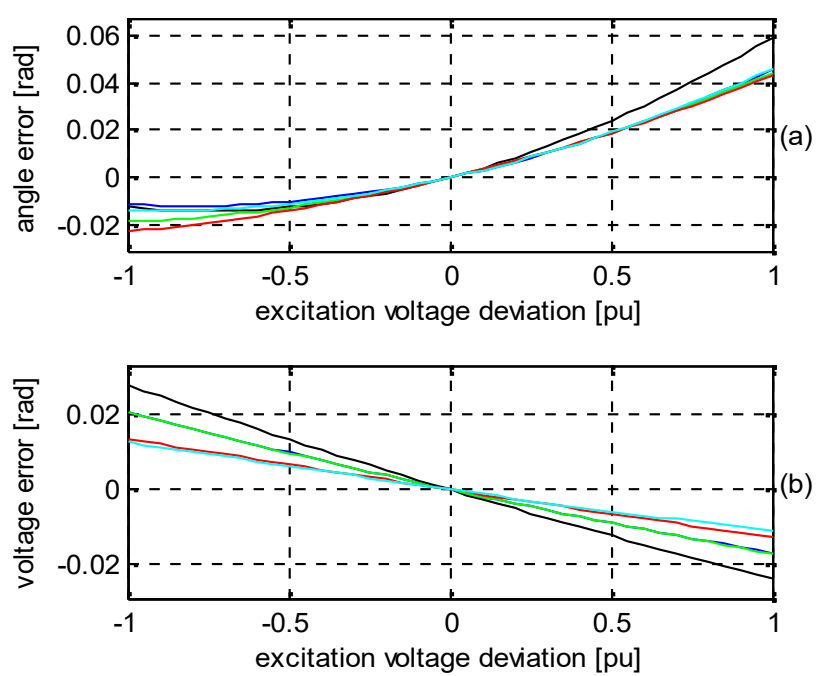

Fig. 10. Rotor angle error (a) and stator voltage error (b) between N7OM and L3OM steady states for deviation of field excitation voltage from $v_{\mathrm{f} \Delta}=-1.0[\mathrm{pu}]$ to $v_{\mathrm{f} \Delta}=+1.0[\mathrm{pu}]$ around nominal value for turbo type SG of nominal powers $\mathrm{Sn}=25 \mathrm{MVA}$ (black), 75 MVA (blue), 160 MVA (green), 555 MVA (red), 915 MVA (cyan).

From the results obtained from the analysis of all SG, it can be concluded:

- the pu steady-state error in the stator voltage is mainly smaller than the pu steady-state error in the rotor angle, - for standard SG in the power system, the influence of the mechanical torque on the steady-state errors is larger than the influence of the excitation voltage,

- the influence of the mechanical torque on the dynamical error (Fig. 11) is always larger than the influence of the excitation voltage. 


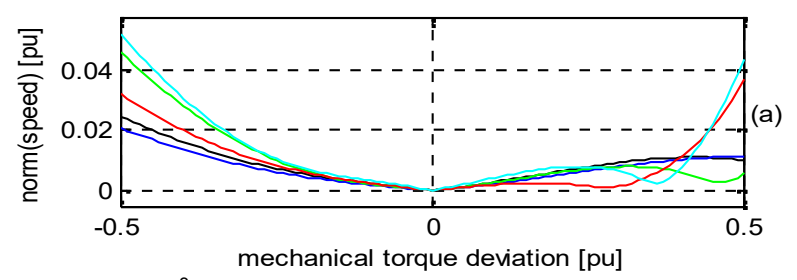

$\times 10^{-3}$

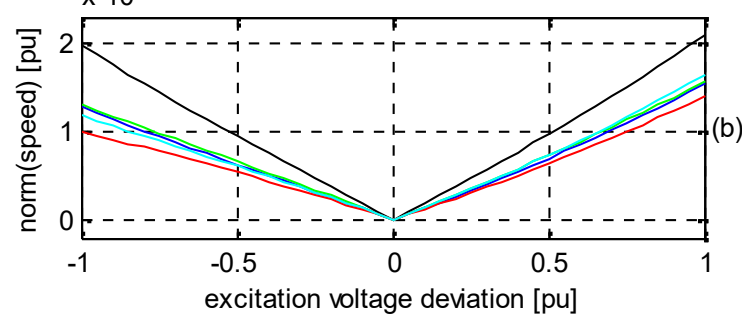

Fig. 11. Square root of integral squared error ("norm(speed)") between rotor speed transients of $\mathrm{N} 7 \mathrm{OM}$ and $\mathrm{L} 3 \mathrm{OM}$ for: (a) step changes of mechanical torque and (b) step changes of field excitation for turbo type SG of nominal powers $\mathrm{Sn}=25$ MVA (black), 75 MVA (blue), 160 MVA (green), 555 MVA (red), 915 MVA (cyan).

On a basis of obtained results, it can be approximated that by mechanical torque deviations smaller than $30 \%$ around the nominal operating point:

- the steady-state error in the rotor angle is always smaller than $10 \%$ and

- the steady-state error in the stator voltage is always smaller than $5 \%$.

We can approximate that by excitation voltage deviations smaller than $60 \%$ around the nominal operating point:

- the steady-state error in rotor angle is always smaller than $15 \%$ and

- the steady-state error in the stator voltage is always smaller than $2 \%$.

\section{QUALITATIVE COMPARISON OF N7OM AND L3OM}

Applicability with feasibility and accuracy of the studied SG's models was evaluated for representative scenarios as objectively as possible. The evaluation is based on the systemic numerical calculations for different SG in the entire operating range. For each generator, N7OM and a group of L3OMs were determined. They covered the entire operating range. In this way, qualitative estimates of usability of L3OM in different categories are obtained.

On a basis of the theoretical analysis and the numerical analysis, the quality grades for the both models were established. An associate scale consists of the seven grades marked from "---." to "+++". The following ten investigated categories were evaluated:

- accuracy in small operating range around steady-state,

- accuracy in entire operating range,

- complexity of models' structure (order, non-linearities),

- number of SG's data for models' parameters calculation

- obtained models' output variables,

- suitability of models for numerical simulations (computing demand, integration step size and integration method),

- suitability of models for theoretical analysis,

- suitability of models for eigenvalue analysis,

- suitability of models for control system design and synthesis,
- possibility to comprehend saturation phenomena.

Evaluation of proposed L3OM for all the investigated categories is presented in Table X.

TABLE X. ASSESMENT OF STUDIED MODELS.

\begin{tabular}{|c|c|c|}
\hline Sphere of activity & N7OM & L3OM \\
\hline Accuracy in small range & +++ & +++ \\
\hline Accuracy in entire range & +++ & - \\
\hline Complexity & -- & +++ \\
\hline Necessary SG's data & --- & + \\
\hline Obtained output variables & +++ & + \\
\hline Numerical simulations & + & +++ \\
\hline Theoretical analysis & -- & +++ \\
\hline Eigenvalue analysis & --- & +++ \\
\hline Control design and synthesis & -- & +++ \\
\hline Saturation phenomena & ++ & -- \\
\hline
\end{tabular}

\section{CONCLUSIONS}

The main contribution of the paper is detailed theoretical and numerical study of certain characteristics of L3OM and its applicability and accuracy in different conditions. On the basis of the defined characteristics, the steady-state and dynamic integral squared errors can be estimated within the theoretical and numerical evaluation. They mainly arise as consequences of the simplification and linearization of the basic full order non-linear model. The presented results improve knowledge for improved decisions regarding design, synthesis and testing of the SG's control systems (e.g. power system stabilizers [11]).

The secondary contribution of the paper is the unified presentation with direct comparison of the complex backgrounds, advantages and disadvantages of existing N7OM and L3OM. This consideration includes accuracy, complexity, electromagnetic and electromechanical characteristics and suitability for simulation and analysis. The inferred knowledge offers auxiliary support and convenience to professionals for selecting the appropriate model in the considered operating conditions.

\section{APPENDIX A}

TABLE A-I. MANUFACTURER'S DATA: TURBO SG $S_{\mathrm{n}}=25$ MVA \begin{tabular}{|c|c|c|c|}
\hline$S_{\mathrm{n}}=25[\mathrm{MVA}]$ & $U_{\mathrm{n}}=13.8[\mathrm{kV}]$ & $I_{\mathrm{n}}=1.05[\mathrm{kA}]$ & $\cos \varphi_{\mathrm{n}}=0.8$ \\
\hline
\end{tabular} \begin{tabular}{|l|l|l|l|}
\hline$L_{\mathrm{d}}=1.25[\mathrm{pu}]$ & $L_{\mathrm{q}}=1.22[\mathrm{pu}]$ & $L_{\mathrm{d}}{ }^{\prime}=0.23[\mathrm{pu}]$ & $L_{\mathrm{d}}{ }^{\prime \prime}=0.12[\mathrm{pu}]$ \\
\hline
\end{tabular} \begin{tabular}{l|l|l|l}
$l_{\mathrm{d}}=0.114[\mathrm{pu}]$ & $l_{\mathrm{q}}=0.114[\mathrm{pu}]$ & $R_{\mathrm{e}}=0.02[\mathrm{pu}]$ & $L_{\mathrm{e}}=0.4[\mathrm{pu}]$ \\
\hline
\end{tabular} \begin{tabular}{r|r|r|r}
$R_{\mathrm{S}}=0.0014[\mathrm{pu}]$ & $R_{\mathrm{F}}=0.0007[\mathrm{pu}]$ & $H=3.34[\mathrm{pu}]$ & $D=2[\mathrm{pu}]$
\end{tabular} \begin{tabular}{c|c|c|c|}
\hline$R_{\mathrm{D}}=0.01[\mathrm{pu}]$ & $R_{\mathrm{Q}}=0.05[\mathrm{pu}]$ & $T_{\mathrm{d} 0}^{\prime}=4.75[\mathrm{~s}]$ & $\omega_{\mathrm{s}}=2 \pi 50\left[\mathrm{~s}^{-1}\right]$ \\
\hline
\end{tabular}

TABLE A-II. MANUFACTURER'S DATA: TURBO SG $S_{\mathrm{n}}=75$ MVA.
\begin{tabular}{|c|c|c|c|}
\hline$S_{\mathrm{n}}=75[\mathrm{MVA}]$ & $U_{\mathrm{n}}=13.8[\mathrm{kV}]$ & $I_{\mathrm{n}}=3.14[\mathrm{kA}]$ & $\cos \varphi_{\mathrm{n}}=0.8$ \\
\hline$L_{\mathrm{d}}=1.05[\mathrm{pu}]$ & $L_{\mathrm{q}}=0.98[\mathrm{pu}]$ & $L_{\mathrm{d}}{ }^{\prime}=0.18[\mathrm{pu}]$ & $L_{\mathrm{d}}{ }^{\prime}=0.13[\mathrm{pu}]$ \\
\hline$l_{\mathrm{d}}=0.07[\mathrm{pu}]$ & $l_{\mathrm{q}}=0.07[\mathrm{pu}]$ & $R_{\mathrm{e}}=0.02[\mathrm{pu}]$ & $L_{\mathrm{e}}=0.4[\mathrm{pu}]$ \\
\hline$R_{\mathrm{s}}=0.0031[\mathrm{pu}]$ & $R_{\mathrm{F}}=0.0005[\mathrm{pu}]$ & $H^{\prime}=4.13[\mathrm{pu}]$ & $D=2[\mathrm{pu}]$ \\
\hline$R_{\mathrm{D}}=0.01[\mathrm{pu}]$ & $R_{\mathrm{Q}}=0.05[\mathrm{pu}]$ & $T^{\prime}{ }_{\mathrm{d} 0}=6.1[\mathrm{~s}]$ & $\omega_{\mathrm{s}}=2 \pi 50\left[\mathrm{~s}^{-1}\right]$ \\
\hline
\end{tabular}

TABLE A-III. MANUFACTURER'S DATA: TURBO SG $S_{\mathrm{n}}=160$ MVA.

\begin{tabular}{|c|c|c|c|}
\hline$S_{\mathrm{n}}=160[\mathrm{MVA}]$ & $U_{\mathrm{n}}=15[\mathrm{kV}]$ & $I_{\mathrm{n}}=6.17[\mathrm{kA}]$ & $\cos \varphi_{\mathrm{n}}=0.8$ \\
\hline$L_{\mathrm{d}}=1.7[\mathrm{pu}]$ & $L_{\mathrm{q}}=1.64[\mathrm{pu}]$ & $L_{\mathrm{d}}{ }^{\prime}=0.24[\mathrm{pu}]$ & $L_{\mathrm{d}}{ }^{\prime}=0.18[\mathrm{pu}]$ \\
\hline$l_{\mathrm{d}}=0.15[\mathrm{pu}]$ & $l_{\mathrm{q}}=0.15[\mathrm{pu}]$ & $R_{\mathrm{e}}=0.02[\mathrm{pu}]$ & $L_{\mathrm{e}}=0.4[\mathrm{pu}]$ \\
\hline$R_{\mathrm{S}}=0.0011[\mathrm{pu}]$ & $R_{\mathrm{F}}=0.0007[\mathrm{pu}]$ & $H=2.37[\mathrm{pu}]$ & $D=2[\mathrm{pu}]$ \\
\hline$R_{\mathrm{D}}=0.013[\mathrm{pu}]$ & $R_{\mathrm{Q}}=0.054[\mathrm{pu}]$ & $T^{\prime}{ }_{\mathrm{d} 0}=5.9[\mathrm{~s}]$ & $\omega_{\mathrm{s}}=2 \pi 50\left[\mathrm{~s}^{-1}\right]$ \\
\hline
\end{tabular}

TABLE A-IV. MANUFACTURER'S DATA: TURBO SG $S_{\mathrm{n}}=555$ MVA. \begin{tabular}{|l|l|l|l|}
\hline$S_{\mathrm{n}}=555[\mathrm{MVA}]$ & $U_{\mathrm{n}}=24[\mathrm{kV}]$ & $I_{\mathrm{n}}=13.37[\mathrm{kA}]$ & $\cos \varphi_{\mathrm{n}}=0.9$ \\
\hline
\end{tabular} \begin{tabular}{|c|c|c|c|}
\hline$L_{\mathrm{d}}=1.81[\mathrm{pu}]$ & $L_{\mathrm{q}}=1.76[\mathrm{pu}]$ & $L_{\mathrm{d}}{ }^{\prime}=0.3[\mathrm{pu}]$ & $L_{\mathrm{d}}{ }^{\prime \prime}=0.23[\mathrm{pu}]$ \\
\hline
\end{tabular} \begin{tabular}{|l|l|l|l|}
\hline$l_{\mathrm{d}}=0.15[\mathrm{pu}]$ & $l_{\mathrm{q}}=0.15[\mathrm{pu}]$ & $R_{\mathrm{e}}=0.02[\mathrm{pu}]$ & $L_{\mathrm{e}}=0.4[\mathrm{pu}]$ \\
\hline
\end{tabular} \begin{tabular}{|c|c|c|c|c|}
\hline$R_{\mathrm{S}}=0.003[\mathrm{pu}]$ & $R_{\mathrm{F}}=0.0006[\mathrm{pu}]$ & $H=3.52[\mathrm{pu}]$ & $D=2[\mathrm{pu}]$ \\
\hline$R_{\mathrm{D}}=0.0284[\mathrm{pu}$ & $R_{\mathrm{Q}}=0.0299[\mathrm{pu}$ & $T$ & $=8.0[\mathrm{~s}]$ & $\omega_{\mathrm{S}}=2 \pi 50[\mathrm{~s}$ \\
\hline
\end{tabular} \begin{tabular}{|l|l|l|l|}
\hline$R_{\mathrm{D}}=0.0284[\mathrm{pu}]$ & $R_{\mathrm{Q}}=0.0299[\mathrm{pu}]$ & $T_{\mathrm{d} 0}^{\prime}=8.0[\mathrm{~s}]$ & $\omega_{\mathrm{S}}=2 \pi 50\left[\mathrm{~s}^{-1}\right]$ \\
\hline
\end{tabular} 
TABLE A-V. MANUFACTURER'S DATA: TURBO SG $S_{\mathrm{n}}=911$ MVA

\begin{tabular}{|c|c|c|c|}
\hline$S_{\mathrm{n}}=911[\mathrm{MVA}]$ & $U_{\mathrm{n}}=26[\mathrm{kV}]$ & $I_{\mathrm{n}}=20.25[\mathrm{kA}]$ & $\cos \varphi_{\mathrm{n}}=0.9$ \\
\hline$L_{\mathrm{d}}=2.04[\mathrm{pu}]$ & $L_{\mathrm{q}}=1.96[\mathrm{pu}]$ & $L_{\mathrm{d}}{ }^{\prime}=0.27[\mathrm{pu}]$ & $L_{\mathrm{d}}{ }^{\prime}=0.19[\mathrm{pu}]$ \\
\hline$l_{\mathrm{d}}=0.154[\mathrm{pu}]$ & $l_{\mathrm{q}}=0.154[\mathrm{pu}]$ & $R_{\mathrm{e}}=0.02[\mathrm{pu}]$ & $L_{\mathrm{e}}=0.4[\mathrm{pu}]$ \\
\hline$R_{\mathrm{S}}=0.001[\mathrm{pu}]$ & $R_{\mathrm{F}}=0.001[\mathrm{pu}]$ & $H=1.66[\mathrm{pu}]$ & $D=2[\mathrm{pu}]$ \\
\hline$R_{\mathrm{D}}=0.01[\mathrm{pu}]$ & $R_{\mathrm{Q}}=0.05[\mathrm{pu}]$ & $T^{\prime}{ }_{\mathrm{d} 0}=6.0[\mathrm{~s}]$ & $\omega_{\mathrm{S}}=2 \pi 50\left[\mathrm{~s}^{-1}\right]$ \\
\hline
\end{tabular}

\section{REFERENCES}

[1] P. M. Anderson, A. A. Fouad, Power System Control and Stability. The Iowa State University Press: Ames, Iowa, 1977.

[2] P. Kundur, Power System Stability and Control. McGraw-Hill, Inc: New York, 1994.

[3] I. Boldea, Synchronous Generators. Taylor \& Francis Group: Boca Raton, 2016.

[4] W. G. Heffron, R. A. Phillips, "Effect of a modern amplidyne voltage regulator on underexcited operation of large turbine generators", AIEE Transactions, vol. 71, pp. 692-697, 1952. [Online]. Available: http://dx.doi.org/10.1109/aieepas.1952.4498530

[5] K. Law, D. J. Hill, N. R. Godfrey, "Robust controller structure for coordinated power system voltage regulator and stabilizer design", IEEE Trans. Control Syst. Technol., vol. 2, no. 3, pp. 220-232, 1994. [Online]. Available: http://dx.doi.org/10.1109/87.317979

[6] S. Roy, "Influence of amortisseurs on stabiliser design requirements for damping local oscillations of a generator", IEEE Trans. on Power Systems, vol. 14, no. 3, pp. 935-943, 1999. [Online]. Available: http://dx.doi.org/10.1109/59.780906

[7] M. Soliman, D. Westwick, O. P. Malik, "Identification of HeffronPhillips model parameters for synchronous generators operating in closed loop", IET Generation, Transmission \& Distribution, vol. 2, no. 4, pp. 530-241, 2008. [Online]. Available: http://dx.doi.org/ 10.1049/iet-gtd:20070405

[8] G. Gurrala, I. Sen, "Power system stabilizers design for interconnected power systems", IEEE Trans. on Power Systems., vol. 25, no. 2, pp. 1042-1051, 2010. [Online]. Available: http://dx.doi.org/10.1109/TPWRS.2009.2036778

[9] J. Ma, H. J.Wang, K. L. Lo, "Clarification on power system stabiliser design", IET Generation, Transmission \& Distribution, vol. 7, no. 9, pp. 973-981, 2013. [Online]. Available: http://dx.doi.org/ 10.1049/iet-gtd.2012.0219

[10] C. M. S. Neto, F. B. Costa, R. L. A. Ribeiro, R. L. Barreto, T. O. A Rocha, "Wavelet-based power system stabilizer", IEEE Trans. Industrial Electronics, vol. 62, no. 12, pp. 7360-7369, 2015 [Online]. Available: http://dx.doi.org/10.1109/TIE.2015.2454482

[11] J. Ritonja, "Self-tuning control for synchronous machine", Elektronika ir Elektrotechnika, vol. 21, no. 4, pp. 7-12, 2015. [Online]. Available: http://dx.doi.org/10.5755/j01.eee.21.4.12773

[12] M. Azubalis, V. Azubalis, A. Jonaitis, "Practical assessment of synchronous generator dynamic model parameters", Elektronika ir Elektrotechnika, vol. 16, no. 10, pp. 33-36, 2010.

[13] M. Karrari, O. P. Malik, "Identification of Physical parameters of a synchronous generator from online measurement", IEEE Trans. on Energy Conversion, vol. 19, no. 2, pp. 407-415, 2004. [Online] Available: http://dx.doi.org/10.1109/TEC.2003.822296

[14] IEEE Guide for Synchronous Generator Modeling - Practices and Applications in Power System Stability Analyses, IEEE Standard 1110, 2002.

[15] Rotating Electrical Machines - Methods for Determining Synchronous Machine Quantitites from Tests, IEC Standard 60034-4, 2008. 